\title{
Ocular microtremor in patients with idiopathic Parkinson's disease
}

\author{
Ciaran Bolger, Stana Bojanic, Noirin F Sheahan, Davis Coakley, James F Malone
}

\begin{abstract}
Abnormalities in the oculomotor control mechanism of patients with idiopathic Parkinson's disease are well recognised. In this study the effect of Parkinson's disease on tonic output from oculomotor nuclei was studied by using oculomicrotremor as an index of such output. Oculomicrotremor readings were taken from 22 parkinsonian patients and 22 normal healthy volunteers using the piezoelectric strain gauge technique. There was a slower overall tremor frequency, baseline, and burst frequency in the parkinsonian group. There was also a significant increase in the duration of baseline, with a decrease in the number of bursts a second and a decrease in average duration of bursts in the patient group compared with the normal group. One patient, whose medication was withdrawn, showed a marked decrease in mean frequency and baseline frequency with a decrease in number of bursts and increase in baseline duration compared with readings taken when treatment recommenced. These results suggest that variables measured in oculomicrotremor are altered compared with normal subjects, reflecting altered tonic output from oculomotor nuclei in patients with idiopathic Parkinson's disease.
\end{abstract}

(F Neurol Neurosurg Psychiatry 1999;66:528-531)

Keywords: Parkinson's disease; oculomicrotremor; dopamine; piezoelectric strain gauge

Mercer's Institute for Research on Ageing, $\mathrm{St}$ James's Hospital, Dublin, Ireland

N F Sheahan

D Coakley

J F Malone

Correspondence to: Miss S Bojanic, Room 1, Academic Centre, Frenchay Hospital, Bristol BS16 1LE, UK. Telephone 0044117 9701212 ext 3584; fax 0044 117975 3979; email

sbojanic@neurosurgery. demon.co.uk

Received 25 March 1998 and in revised form 23 October 1998

Accepted 3 November 1998

disease saccades are normal when directed to a novel target (reflexive saccades) ${ }^{3}$ or even to the mirror image of the target location (antisaccade). ${ }^{3}$ However, patients exhibit a reduction in the amplitude of memory guided ${ }^{1}$ and predictive saccades, ${ }^{4}$ as well as multistepping hypometria in these cases. ${ }^{1}$ Indeed the spatial error of parkinsonian saccades does not invariably take the form of hypometria when part of a rapid sequence of eye movements and they can be hypermetric relative to the target location. ${ }^{5}$ Abnormalities in a smooth pursuit gain have also been documented. ${ }^{6}$

Oculomotor units exhibit continuous activity even when the eye is at rest or in the primary position. Constant oculomotor unit activity produces a fine high frequency eye tremor recordable at the eye surface. ${ }^{7}$ This neurologically generated tremor (oculomicrotremor) is constantly present in all subjects and is entirely involuntary. ${ }^{8}$ Tonic activity in the frontal eye fields is in part responsible for the constant output from the oculomotor units, ${ }^{9}$ and activity in this state is known to be affected by dopamine depletion in Parkinson's disease. ${ }^{10}$

The purpose of this research was firstly to investigate the effect of Parkinson's disease on tonic output from oculomotor nuclei, by using oculomicrotremor as an index of such output, and secondly, to investigate the possibility of using oculomicrotremor as an objective measure of neuronal activity in these patients.

\section{Methods}

PATIENTS

Twenty two patients with idiopathic Parkinson's disease were studied (mean age 68 (SD 10.45) years). All of the patients were being treated with dopaminergic drugs and none were taking psychotropic or tranquillising agents. None of the patients had any evidence of oculomotor dysfunction on clinical examination. At the time of recording, patients were subjected to a full neurological examination including a mini mental state examination (none scoring below 28). They were also scored on the bradykinesia subsection of the Webster scale. ${ }^{11}$ Patients with a score of 0 or 1 were considered "on" while those with a score of 2 or 3 were considered "OFF". Twelve patients were "on" (mean age 67 (SD 11) years) and 10 patients were considered "off" despite medication (mean age 70 (SD 10) years). Clinical examinations of the patients were repeated fully at each recording session.
CONTROL GROUP

Twenty two neurologically normal healthy volunteers were included for study (mean age 68 (SD 10.21) years). The group consisted of 12 
A comparison of the seven indices of oculomicrotremor activity between the Parkinsons and normal groups

\begin{tabular}{|c|c|c|c|c|c|c|c|c|}
\hline & & $\begin{array}{l}\text { Overall } \\
\text { frequency }(\mathrm{Hz})\end{array}$ & $\begin{array}{l}\% \text { Of record occupied } \\
\text { by baseline }\end{array}$ & $\begin{array}{l}\text { Frequency of } \\
\text { baseline (Hz) }\end{array}$ & $\begin{array}{l}\text { Number of bursts } \\
\text { per second }\end{array}$ & $\begin{array}{l}\text { Frequency of } \\
\text { bursts }(\mathrm{Hz})\end{array}$ & $\begin{array}{l}\text { Duration of } \\
\text { bursts (ms) }\end{array}$ & $\begin{array}{l}\text { Duration of } \\
\text { baseline (ms) }\end{array}$ \\
\hline \multirow[t]{2}{*}{ Parkinson's disease $(n=22)$} & Mean & 67.68 & 78.01 & 73.74 & 4.25 & 67.9 & 51.65 & 215.91 \\
\hline & SD & 10.75 & 12.78 & 15.51 & 2.35 & 12.88 & 7.03 & 138.63 \\
\hline \multirow{2}{*}{ Normal $(n=22)$} & Mean & 81.64 & 49.45 & 87.97 & 8.26 & 75.76 & 61.24 & 64.79 \\
\hline & SD & 6.1 & 9.95 & 8.47 & 1.2 & 5.32 & 6.51 & 21.04 \\
\hline \multirow[t]{2}{*}{ Statistics } & $(\mathrm{p}<)$ & 0.00001 & 0.00001 & 0.0013 & 0.0001 & 0.0422 & 0.0002 & 0.00001 \\
\hline & $U$ & 54 & 21 & 105 & 30.5 & 155.5 & 82 & 33 \\
\hline
\end{tabular}

men and 10 women. All were free from medication and had no evidence of concurrent disease.

RECORDING SESSION

Oculomicrotremor was recorded using the piezoelectric strain gauge technique first developed by Bengi and Thomas. ${ }^{12}$ This technique is described in detail elsewhere ${ }^{13}$ and has been shown to provide a reliable estimate of oculomicrotremor activity. ${ }^{14}$ Briefly, the piezoelectric element is mounted in a Perspex rod and its tip is coated with silicone rubber. The subject lies supine with the eyes in the primary position in a normally lit room. The Perspex rod is mounted on a headframe and lowered directly on to the scleral surface, which has been anaesthetised with $0.5 \%$ proxymethacaine hydrochloride solution. The eyelids are retracted with adhesive tape. Probe placement is judged by visual inspection and by listening to the signal being recorded, using audio cassette headphones.

The signal from each probe is passed to a conditioning unit and amplified (differential amplifier with $40 \mathrm{~dB}$ common mode refection ratio, flat (within $1 \mathrm{~dB}$ ) frequency response between 20 and $150 \mathrm{~Hz}$ ) and stored on audiotape using an adapted Sony Walkman for later retrieval and analysis. This system has a signal/ noise ratio of $>23 \mathrm{~dB}$ and the resolution is $<1 \%$ of the dynamic range, or $25 \mathrm{~nm}$. The frequency response is flat between $20 \mathrm{~Hz}-150 \mathrm{~Hz}$ with $<2 \mathrm{~dB}$ deviation from peak response.

OMT records were analysed by visual inspection by an investigator who was unaware of the clinical status of the subject. Normal eye tremor activity consists of an irregular baseline tremor superimposed on which are regular sinusoidal episodes of activity termed bursts. The OMT record is analysed visually and the bursts are easily distinguishable, possessing a greater amplitude than the rest of the microtremor and a packet-like appearance against the baseline tremor. Studies have shown that the bursts are of a near sinusoidal oscillation at a frequency of $80 \mathrm{~Hz}$ (range $75 \mathrm{~Hz}-115 \mathrm{~Hz}$ ). ${ }^{8}$ The baseline pattern is irregular with the mean frequency being $92 \mathrm{~Hz}$ (range $70 \mathrm{~Hz}-126$ $\mathrm{Hz}){ }^{14}$ The mean interval between the bursts is in the order of $70 \mathrm{~ms} .{ }^{14}$ Seven indices of OMT activity were analysed. These were overall frequency, the percentage of the record occupied by baseline activity, the frequency of baseline activity, the number of bursts occurring per second, the frequency content of those bursts, the average duration of a burst, and the average duration of the baseline (interburst period). Analysis was based on 5 seconds of OMT activity which was derived at random from a 30 second record, as previously described by Bolger. ${ }^{14}$ Recordings were made from both eyes independently. The results for each eye were then combined to yield a subject's result. The seven indices measured from each recording were compared between the patient and control groups using the Mann-Whitney $U$ test.

\section{Results}

The table gives the mean results for both the control and Parkinson's disease groups. The mean overall frequency in the control group was 81.64 (SD 6.10), range 72-91.8, median 83 whereas the mean in the parkinsonian group was 67.68 (SD 10.75), range 43-84, median 70.50 and this difference was significant $(U=54.0, \mathrm{df}=21, \mathrm{p}<0.00001)$. This difference is reflected in a reduction in the frequency of both baseline and burst components of overall frequency in the parkinsonian group $(U=105.0, \mathrm{df}=21, \mathrm{p}<0.0013, U=155.5, \mathrm{df}=21$, $\mathrm{p}<0.042$ respectively). There was also a significant increase in the amount of record occupied by baseline activity in the parkinsonian group $(U=21.0, \mathrm{df}=1, \mathrm{p}<0.00001)$. This is reflected in both a significant reduction in the number of bursts occurring per second $(U=30.5, \mathrm{df}=21$, $\mathrm{p}<0.0001)$ and a decrease in the average duration of the bursts that were present ( $\mathrm{U}=82.0$, $\mathrm{df}=21, \mathrm{p}<0.0002)$. There was a corresponding increase in the average period between bursts (duration of baseline) ( $U=-33.0, \mathrm{df}=21$, $\mathrm{p}<0.00001$ ). Thus, not only do parkinsonian patients exhibit an eye tremor which is significantly slower than that seen in normal subjects, but this tremor also has an abnormal pattern (figure).

EYE TREMOR RECORD AND CLINICAL STATUS Abnomalities of eye tremor activity in parkinsonian patients are subject to the influence of the clinical state of the patient. Those judged to be "off" are significantly different from patients who are "on". Patients who are "off" have a significantly lower eye tremor frequency than those judged to be "on". The mean peak count frequency in the "off" group was 58.88 (SD 10.35) whereas that in the "on" group was 73.78 (SD 5.55) $(U=12.0, \mathrm{df}=8, \mathrm{p}<0.0019)$.

This is explained by a reduction in the frequency content of burst activity alone ( $U=$ $15.0, \mathrm{df}=8, \mathrm{p}<0.0036$ ), there being no significant effect on baseline frequency content. In addition, there was a significant increase in the amount of record occupied by baseline activity $(\mathrm{U}=25.0, \mathrm{df}=8, \mathrm{p}<0.025)$. It should by noted that although there is a marked abnormality of the eye tremor activity in the "off" group, the 


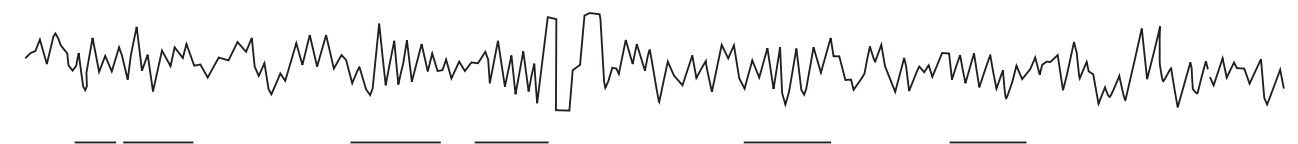

A

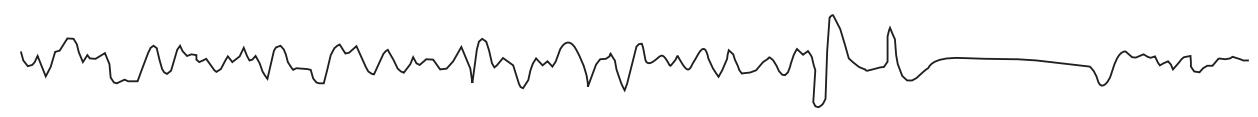

B

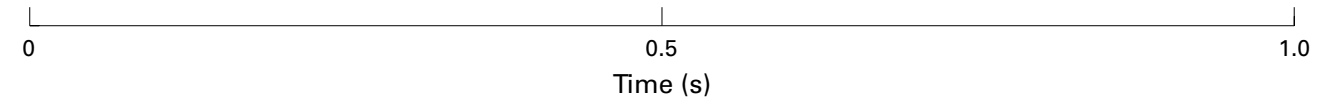

(A) Example of a normal oculomicrotremor reading and (B) an OMT reading from a parkinsonian patient. The oculomicrotremor signal appears as an irregular oscillatory movement with intermittent burst-like components. The horizontal bars represent bursts and the area between the bursts is termed the baseline. Both recordings were subjected to the same filter system in the conditioning unit.

"on" group exhibits indices of oculomicrotremor activity which remain markedly different from those seen in normal subjects.

WITHDRAWAL OF MEDICATION

In one patient medication was withdrawn to investigate a coincident problem of hypertension. Oculomicrotremor records were obtained from this patient on two occasions. The first record was obtained 48 hours after the cessation of dopamine treatment and the second 24 hours after recommencement of treatment. In that period, the patient's clinical state changed from being "off" to being "on". The first record of oculomicrotremor activty was markedly abnormal with an overall frequency of $66.5 \mathrm{~Hz}$. This was reflected in a marked decrease in baseline frequency. He also had an abnormally large percentage of his record occupied by baseline activity (77\%) with a reduced number of bursts (4 bursts per second) and an increase in the mean period between bursts $(171 \mathrm{~ms})$. However, 24 hours later, corresponding to 24 hours after recommencement of treatment, the overall frequency had increased to $78.5 \mathrm{~Hz}$, with a decrease in the percentage of his record occupied by baseline activity $(55.8 \%)$, an increase in the number of bursts ( 8.5 bursts per second), and a decrease in the mean period between bursts $(171 \mathrm{~ms})$.

\section{Discussion}

It is well established that parkinsonism is associated with oculomotor control abnormalities. ${ }^{2}$ Recent electro-oculographic studies on these patients show abnormalities of vestibular and oculomotor systems which are not correlated with clinical features. Deficits in the caloric nystagmus induced in these patients cannot be explained on the basis of an inability to initiate voluntary movement. ${ }^{15}$ Although a good correlation exists between the extent of oculomotor and peripheral motor dysfunction in Parkinson's disease, ${ }^{16}$ many differences exist between the oculomotor and peripheral motor systems in terms of physiology. Analysis of oculomicrotremor in parkinsonian patients has disclosed major differences between these patients and normal healthy volunteers. This reflects abnormalities of oculomotor function in these patients. The finding of such abnormalities shows that oculomotor dysfunction in parkinsonian patients cannot be purely explained on the basis of problems with the initiation of voluntary movement which would support the finding of abnomalities in the caloric system. It is unclear whether or not this finding shows a direct striatal effect on the oculomotor system as other authors have concluded ${ }^{16}$ or whether the effect of dopamine depletion on other areas of the CNS known to have a tonic output to the oculomotor neurons such as the frontal eye fields are responsible for this change. ${ }^{9} \mathrm{~A}$ distinct anatomical connection exists between the frontal eye fields and the basal ganglia and this may provide a pathway for mediation of the effects of dopamine depletion, although the basal ganglia may have a more direct input to oculomotor areas. 
An interesting aspect of the work to date has been the demonstration of the sensitivity of movement abnormalities to dopamine concentrations. Dopamine sensitivity has been shown by both direct administration of levodopa and by alterations in the movement abnormalities seen with the "on/off" phenomenon, this phenomenon being due to fluctuation in dopamine concentrations in the striatum. ${ }^{17}$ In MPTP induced Parkinson's syndrome, abnormalities of the saccadic system are reversible with levodopa, both in humans and in primates. ${ }^{10}$ Abnormalities of the saccadic system seen in idiopathic Parkinson's disease are also dopamine responsive and vary with the “on/off” syndrome. ${ }^{6}$ However, dopamine sensitivity of smooth pursuit abnormalities has been less clearly seen with conflicting effects of the "on/off" phenomenon being reported. ${ }^{8}$ The differences reported here between distinct clinical groups of patients are broadly supportive of evidence that oculomotor dysfunction fluctuates in patients with the "on" and "off" syndrome and therefore that abnormalities in the oculomotor system may be directly related to striatal dopamine concentrations. Our study of dopamine withdrawal in one patient shows a marked response of oculomotor abnormalities to levodopa administration. The increase in oculomotor activity cannot be explained on the basis of day to day variation as overall frequency, frequency content of baseline, and average burst duration have been shown to have no significant day to day variation. ${ }^{18}$ Whereas these results are being reported in a comparatively few patients, particularly the dopamine withdrawal in the one patient, the findings would suggest that further studies on those with the "on/off" syndrome or on the effects of levodopa withdrawal are warranted.

It has been difficult to identify indices of oculomicrotremor activity which may serve as an objective test of bradykinesia in parkinsonian patients. Although the abnormality rate is high $(82 \%$ for all patients) no particular index adequately differentiates between the distinct clinical groups. It may well be that group studies mask this use of oculomicrotremor recording due to between patient variations but that for an individual patient, serial oculomicrotremor recordings will yield information on dopaminergic reponsiveness for that patient.
In conclusion, it seems that abnormalities of oculomotor function cannot be explained purely on the basis of an inability to initiate voluntary movement. Tonic oculomotor activity is also abnormal and this abnormality is similar to those described for other oculomotor functions. Furthermore, there is some evidence that these abnormalities are responsive to dopamine. Oculomicrotremor recording may prove a useful objective method for the assessment of these patients. Records are obtained with ease and the equipment required to obtain adequate records is portable.

This work was supported by the Health Research Board, Ireland.

1 Crawford TJ, Henderson L, Kennard C. Abnormalities of non-visually guided eye movements in Parkinson's disease. Brain 1989;112:1573-86.

2 White OB, Saint-Cyr JA, Tomilson D, et al. Oculomotor deficits in Parkinson's disease. III Co-ordination of eye and head movements. Brain 1988;111:115-29.

3 Lueck CJ, Tanyeri S, Crawford TJ, et al. Antisaccades and remembered saccades in Parkinson's disease. 7 Neurol Neurosurg Psychiatry 1990;53:284-8.

4 Crawford TJ, Goodrich S, Henderson L, et al. Predictive responses in Parkinson's disease: manual key presses and saccadic eye movements to regular stimulus events. $\mathcal{F} \mathrm{Neu}$ rol Neurosurg Psychiatry 1989;52:1033-42.

5 O'Sullivan E.P, Shaunak S, Henderson L, et al. Abnormalities of predictive saccades in Parkinson's disease. Neuroreport 1997;8:1209-13.

6 Gibson JM, Pimlott R, Kennard C. Oculomotor and manual tracking in Parkinson's disease and the effect of treatment. F Neurol Neurosurg Psychiatry 1987;50:853-60.

7 Alder F.H, Fliegelman F. Influence of fixation on the visual acuity. Arch Ophthal 1934;12:475-83.

8 Coakley D. Minute eye movement and brainstem function. Florida: CRC Press, 1983.

9 Bruce CJ, Goldberg ME, Bushnell MC, et al. Primate frontal eye fields II. F Neurophysiol 1985;54:714-34.

10 Ho VW, Porrino LJ, Crane AM, et al. Metabolic mapping of the oculomotor system in MPTP induced Parkinsonian monkeys. Ann Neurol 1988;23:86-9.

11 Webster DD. Critical analysis of disability in Parkison's Disease. Modern Treatments 1968;5:257-82.

12 Bengi H, Thomas JG. Three electronic methods for recording ocular microtremor. Med Biol Eng 1968;6:171-8.

13 Sheahan N, Coakley D, Hegarty F, et al. Ocular microtremor measurement system: design and performance. Med Biol Eng Comput 1993:31:205-12.

14 Bolger C, Sheahan N, Coakley D, et al. High frequency eye tremor: reliability of measurement. Clinical Physics and Physiological Measurement 1992;13:151-9.

15 Cipparrone L, Ginanneschi A, Degl'Innoccenti F, et al. Electro-oculographic routine examination in Parkinson's disease. Acta Neurol Scand 1988;77:6-11.

16 Gibson J.M, Kennard C. Quantative study of on-off fluctuations in the oculomotor system in Parkinson's disease. $A d v$ Neurol 1986;45:329-33.

17 Ohmoto T. Experimental study on resting tremor and L-dopa induced dyskinesia. Eur Neurol 1987;26:47-55.

18 Sheahan N, Coakley D, Bolger C, et al. Sources of variance in ocular microtremor. Physiol Meas 1994;15:101-6. 